\title{
Incidence of Gallbladder Carcinoma in Thick Walled Gallbladder in Comparison with that of Normal Thickness - A Study of 300 Cases MM HASAN $^{\mathrm{a}}$, SZ LAILA ${ }^{\mathrm{b}}$, MH MAMUN ${ }^{\mathrm{c}}$
}

\begin{abstract}
Summary:
Background: Gall bladder carcinoma (GBC) is the most common biliary tract cancer. Delayed presentation and early spread of tumor made it one of the lethal tumors with poor prognosis.

Objective: The objective of this study is to find out the incidence of $G B C$ in thick walled gall bladder (GB) in comparison with that of normal wall thickness.
\end{abstract}

Methods: This prospective study was carried out in Combined Military Hospital (CMH) Dhaka, CMH Momenshahi and CMH Ghatail during the period of June 2007 to June 2014. A total 300 patients underwent cholecystectomy were studied retrospectively. Diagnosis was confirmed by histopathological examination.

Results: Out of 300 patients 254 (84.88\%) were female (male : female $=1: 5.52$ ), age range 28 to 79 years. Maximum

Inteoduction:

Gallbladder carcinoma (GBC) is the most common biliary tract cancer, accounting for $3 \%$ of all tumors. ${ }^{1} \mathrm{GBC}$ is hard to detect and diagnose in its early stages because it usually has very slight symptoms or is asymptomatic. But once the diagnosis is confirmed, most of these patients often have metastasis and invasion. Furthermore, GBC is not sensitive to radiotherapy and chemotherapy. All of these characteristics made GBC a highly lethal tumor with a 5 years survival rate of less than $5 \%{ }^{2}$ and a median survival of only 3 months. ${ }^{3}$

a. Dr. Md Mahboob Hasan, Lt Colonel, Classified Specialist in surgery, CMH Ghatail, Shaheed Salahuddin Cantonment, Ghatail, Tangail

b. Dr. Syeda Zeenat Laila, Major, Classified Specialist in Paediatrics, Armed Forces Hospital, OKP-5, Kuwait.

c. Dr. Md Monjur Hasan Mamun, Medical Officer (Clinical Neurosurgery), National Institute of Neuroscience \& Hospital, Dhaka.

Address of Correspondence: Md Mahboob Hasan, Lt Colonel, Classified Specialist in Surgery, CMH Ghatail, Shaheed Salahuddin Cantonment, Ghatail, Tangail, Cell: 01723660642, 01715011637, E-mail: drmahboob_surg@yahoo.com.

Received: 22 Nov. 2017

Accepted: 29 Oct. 2016 number of the patients fall into fourth and fifth decades. 42 (14\%) patients were found to have thick walled GB by preoperative sonography and during surgery. Histopathologically 13 (4.33\%) patients were diagnosed as GBC. Maximum patient (52.33\%) had chronic cholecystitis. Incidence of malignancy were higher (84.62\%) in patients having thicke walled $G B$.

Conclusion: GBC may present as focal or diffuse asymmetric wall thickening or even in GB having normal wall thickness. As early diagnosis and effective treatment can significantly reduce the morality and morbidity all specimen should be examined histopathologically.

Key words: Cholecystectomy, Gall bladder carcinoma, Thick walled gall bladder.

(J Bangladesh Coll Phys Surg 2016; 34: 193-198)

Globally, there is a prominent geographical inconsistency in GBC incidence that draws a parallel with the prevalence of cholelithiasis. ${ }^{4}$ Numerous reports propose an association between chronic $S$. typhi carriage and elevated risk of GBC. ${ }^{5}$

Incidental gallbladder carcinoma (IGBC) is defined as GBC suspected for the first time during cholecystectomy or accidentally found on histological examination of the gallbladder (GB). ${ }^{6}$ With the increase of cholecystectomies since the wide acceptance of laparoscopic cholecystectomy (LC), the incidental diagnosis of $\mathrm{GBC}$ is more frequent. ${ }^{7}$ Unsuspected GBC can be discovered incidentally following $1 \%$ of routine cholecystectomies $^{8}$ diagnosed either intra-operatively or subsequent to histological analysis following cholecystectomy. ${ }^{9}$

Diffuse GB wall thickening may be caused by a wide range of GB diseases and extracholecystic pathologic conditions. It can result from a broad spectrum of pathologic conditions, including surgical and nonsurgical diseases. In most cases it's cause can be determined by correlation of the clinical presentation and associated imaging findings. GBC has various 
imaging appearances, ranging from a polypoid intraluminal lesion to an infiltrating mass replacing the $\mathrm{GB}$, and it may also present as diffuse mural thickening. ${ }^{10}$ In this study we tried to find out the incidence of GBC in relation with wall thickness.

\section{Materials and Methods:}

This observational study has been carried out in Combined Military Hospital (CMH) Dhaka, CMH Momenshahi and $\mathrm{CMH}$ Ghatail during the period of June 2007 to June 2014. A total 300 patients underwent cholecystectomy were studied retrospectively. Diagnosis confirmed by histopathological examination. Patients with clinically suspected or diagnosed malignancy and intraoperatively obvious growth with or without signs of metastasis were excluded from the study.

A detailed history was taken from the patients. Physical findings were recorded properly.

Patients diagnosed as GBC received further treatment under hepatobiliary surgeon and oncologist. All the patients were followed up regularly during their stay in the hospital and as out patient.

\section{Results:}

The youngest patient of this series was 28 years and oldest was of 79 years. Male $46(15.12 \%)$ and Female:
254 (84.88\%); Male: Female is 1: 5.52. A total $42(14 \%)$ patients had thick walled GB and 258 (86\%) patients GB had normal wall thickness (Table - 1).

All patients were evaluated by sonography to determine the wall thickness. Thirty six (12\%) patients were found to have thick walled GB. And in $10(3.33 \%)$ patients contracted GB was found (Table-2).

All resected specimen were examined histopathologically. Incidence of GBC were $4.33 \%$. Maximum 157 (52.33\%) patients had features of chronic inflammation. 54 (18\%) specimens revealed nonspecific findings (Table -3$)$.

Incidence of malignancy was higher $(84.62 \%)$ in patients with thick walled GB. Out of 13 cases $10(76.92 \%)$ were female. Incidence were more in patients of $>60$ years of age group $(46.15 \%)$ irrespective of wall thickness (Table-4).

In all 13 malignant cases the initial diagnosis was GB stone in $11(84.62 \%)$ and GB polyp in $2(15.36 \%)$ patients (Table-5).

Out of the all $13 \mathrm{GBC}$, maximum 7 (53.85\%) were well differentiated adenocarcinoma, $4(30.77 \%)$ were moderately differentiated. Only $1(7.96 \%)$ patient each had poorly differentiated and non-specific adenocarcinoma. Invasion was $\mathrm{pT}_{1}$ in $11(84.62 \%)$ and $\mathrm{pT}_{2}$ in 2 (15.38\%) patients (Table-6).

Table-I

\begin{tabular}{lcccccccc}
\multicolumn{7}{c}{ Age and Sex distribution in relation with GB wall thickness (n=300) } \\
Condition of & \multicolumn{7}{c}{ Sex } & \multicolumn{7}{c}{ Age (years) } & Total & Percentage \\
\hline GB Wall & Male & Female & $<40$ & $41-50$ & $51-60$ & $>60$ & & \\
Thick & 07 & 35 & 13 & 18 & 09 & 02 & 42 & $14 \%$ \\
& $(16.67 \%)$ & $(83.33 \%)$ & $(30.95 \%)$ & $(42.56 \%)$ & $(21.43 \%)$ & $(4.76 \%)$ & & \\
Normal & 39 & 219 & 79 & 105 & 59 & 15 & 258 & $86 \%$ \\
& $(15.12 \%)$ & $(84.88 \%)$ & $(30.62 \%)$ & $(40.70 \%)$ & $(22.87 \%)$ & $(5.81 \%)$ & & \\
Total & 46 & 254 & 92 & 123 & 68 & 17 & 300 & 100 \\
& $(15.12 \%)$ & $(84.88 \%)$ & $(30.62 \%)$ & $(40.70 \%)$ & $(22.87 \%)$ & $(5.81 \%)$ & & \\
\hline
\end{tabular}

$\mathrm{M}: \mathrm{F}=1: 5.52$

Table-II

Sonographic findings of $G B$ wall $(n=300)$

\begin{tabular}{lcc} 
Sonographic findings & No. of patients & Percentage $\%$ \\
\hline Normal wall thickness & 254 & 84.67 \\
Thick wall $(>3 \mathrm{~mm})$ & 36 & 12 \\
Contracted GB & 10 & 3.33 \\
\hline
\end{tabular}

* 6 patients had thick walled GB found duting surgery 


\section{Table-III}

Histopathological Diagnosis: $(n=300)$

\begin{tabular}{lcc} 
Histopathological Diagnosis & Total & Percentage $(\%)$ \\
\hline Chronic Cholecystitis & 157 & 52.33 \\
Cholesterosis & 05 & 1.67 \\
Acute Cholecystitis & 11 & 3.67 \\
Epithelial Hyperplasia & 59 & 19.67 \\
Tuberculosis & 01 & 0.33 \\
Carcinoma GB & 13 & 4.33 \\
Non specific findings & 54 & 18 \\
Total & 300 & 100 \\
\hline
\end{tabular}

Table-IV

\begin{tabular}{|c|c|c|c|c|c|c|c|c|}
\hline \multicolumn{9}{|c|}{ Incidence of Ca in comparison to wall thickness $(n=13)$} \\
\hline \multirow{2}{*}{$\begin{array}{l}\text { Condition of } \\
\text { GB Wall }\end{array}$} & \multicolumn{2}{|c|}{ Sex } & \multicolumn{4}{|c|}{ Age (years) } & \multirow[t]{2}{*}{ Total } & \multirow{2}{*}{$\begin{array}{c}\text { Percentage } \\
\%\end{array}$} \\
\hline & Male & Female & $30-40$ & $41-50$ & $51-60$ & $>60$ & & \\
\hline Thick & 03 & 08 & - & 02 & 05 & 04 & 11 & 84.62 \\
\hline Normal & - & 02 & - & - & 01 & 01 & 02 & 15.38 \\
\hline \multirow[t]{2}{*}{ Total } & 03 & 10 & - & 02 & 05 & 06 & 13 & 100 \\
\hline & $(23.08 \%)$ & $(76.92 \%)$ & & (15.38\%) & (38.46\%) & $(46.15 \%)$ & & \\
\hline
\end{tabular}

Table-V

Clinical diagnosis in the 13 cases of gallbladder carcinoma $(n=13)$

\begin{tabular}{lcc} 
Clinical Diagnosis & No. of patients & Percentage $(\%)$ \\
\hline GB stone & 11 & 84.62 \\
GB polyp $>1 \mathrm{Cm}$ & 02 & 15.38 \\
\hline
\end{tabular}

\section{Table-VI}

Histopathological Characteristics of $\mathrm{Ca}(n=13)$

\begin{tabular}{llcc}
\multicolumn{2}{l}{ Histopathological Characteristics } & No. of patients & Percentage (\%) \\
\hline Type & & & \\
& Well differentiated adenocarcinoma & 07 & 53.85 \\
\multicolumn{7}{l}{ Moderately differentiated adenocarcinoma } & 04 & 30.77 \\
& Poorly differentiated adenocarcinoma & 01 & 7.69 \\
& Non-specific adenocarcinoma & 01 & 7.69 \\
& & & \\
& $\mathrm{pT}_{1}$ & 11 & 84.62 \\
& $\mathrm{pT}_{2}$ & 02 & 15.38 \\
\hline
\end{tabular}




\section{Discussion:}

Cancer of the GB is uncommon, although it is the fifth most common gastrointestinal malignancy ${ }^{11}$ and is found incidentally in $1 \%$ to $3 \%$ of cholecystectomy specimens. ${ }^{12} 2.5$ new cases detected per 100,000 inhabitants per year. It has a high mortality rate as its diagnosis is most of times achieved at advanced stages of the disease, because of the scarcity of symptoms. ${ }^{13}$

Countries with a high incidence of GBC include Chile, Poland, India, and Japan. There is also a very high incidence of this cancer among women in Northern India $(21.5 / 100,000)$ and female Native American Indians (14.5/ 100,000). ${ }^{14}$ Our patient was of Bangladeshi (ie, the Indian subcontinent) origin.

The majority of reports suggest that GBC is two to six times more prevalent in women and the incidence peaks in the seventh decade of life ${ }^{15,16}$ In this study out of 13 malignant cases $10(76.92 \%)$ were female. Incidence were more in patients of $>60$ years of age group $(46.15 \%)$ irrespective of wall thickness.

There is a strong association between cholelithiasis and GBC, with gallstones found in nearly $80 \%$ of all cases. Other risk factors for GBC include a calcified GB (known as porcelain gall-bladder), a long common channel, and a chronic typhoid carrier state. Adenomas figure less prominently or not at all in the list of precursors. ${ }^{17}$ Majority of GBC patients have associated gallstones. With the advent of ultrasonography more patients are being diagnosed with gallstones and are being subjected to cholecytectomy. IGBC is found in $0.2-2.9 \%$ of all cholecytectomies done for gallstone disease. ${ }^{18} \mathrm{~A}$ common characteristic is the presence of gallstones and chronic GB inflammation. ${ }^{19}$ Cholelithiasis is found in approximately $85 \%$ of people with GBC. The association between cholelithiasis and GBC ranges from 2.3 to 34.4 in case control studies. ${ }^{20}$ In our study $84.62 \%$ patients of GBC had cholelithiasis which is almost similar to this.

Clinical presentation of the disease is often vague or delayed relative to pathologic progression, contributing to advanced staging and dismal prognosis at the time of diagnosis. ${ }^{21}$ Unfortunately, the preoperative diagnosis of early-stages of gallbladder carcinoma is difficult due to its non-specific symptoms. The symptoms of GBC overlap with the symptoms of gallstones and biliary colic. Sonography is a routinely requested technique for investigating patients with gallbladder symptoms $\mathrm{s}^{22,23}$ has a relatively high sensitivity for the detection of GBC at advanced stages, but it is limited in the diagnosis of early lesions. Although $\mathrm{CT}$ scan is a valuable investigation for suspected cases of GBC with a reported sensitivity of $80 \%$ and $100 \%$, it is not routinely used to investigate patients with GB disease symptoms. Pre-operative diagnosis depends mainly on a high index of clinical suspicion especially in elderly patients with gallstones. Some authors ${ }^{24}$ suggested criteria for early diagnosis of $\mathrm{GBC}$ in presence of the combination of female sex, old age, silent gallstones presenting at late age, abnormal liver function test and thickened wall of the GB on ultrasonic examination (plus criteria), but these criteria are not yet critically evaluated. ${ }^{25}$

GBC may present as focal or diffuse asymmetric wall thickening in $20-30 \%$ of cases. $^{2}$ Diffuse GB wall thickening is a frequently detected finding on crosssectional imaging in clinical practice; this finding can result from a broad spectrum of pathologic conditions. Among these conditions, acute cholecystitis, chronic cholecystitis, GBC, and adenomyomatosis are common diseases that cause diffuse or focal GB wall thickening. ${ }^{26}$ When GBC manifests as wall thickening, it is challenging to diagnose because it mimics the appearance of more common acute and chronic inflammatory conditions of the GB. ${ }^{27}$

According to several authors, the upper limit for normality of the GB wall thickness is $3 \mathrm{~mm}$. However, in patients under inappropriate fasting, the parietal thickness may exceed such a limit because of the organ's smooth muscle con-traction. ${ }^{13} \mathrm{~GB}$ wall thickening is classified as mild (between 4 and $7 \mathrm{~mm}$ ), marked ( $>7$ $\mathrm{mm}$ ), and in focal or diffuse. As a rule, systemic diseases such as heart, renal or hepatic failure cause diffuse and less marked thickening, contrary to tumor lesions that cause focal and more exuberant thickening, frequently greater than $10 \mathrm{~mm} \cdot{ }^{26}$

Ultrasonography is the method of choice for the study of the GB, with a high sensitivity in the detection of wall thickening. ${ }^{13}$ Real-time elastography using acoustic radiation force impulse (ARFI) is a new emerging technique, which uses high intensity focused ultrasound to evaluate the tissue stiffness in the liver, breast, and other organs. ${ }^{28}$ It has also been shown to differentiate between benign and malignant nodules in various organs. ${ }^{29}$ 
Magnetic resonance imaging has been shown to be valuable in the evaluation of GB wall thickening, but it still plays a small diagnostic role. ${ }^{30}$ Because of its high cost and low specificity, MRI is not used to diagnose chronic cholecystitis. ${ }^{31,32}$ In our study 42 (14\%) patients had thick walled GB out of them 36 were diagnosed sonographically and 6 cases were found dering surgery. On histopathological examination 11 (84.62\%) GBC cases had thick walled GB which is very high.

GBC is associated with macroscopic abnormalities in all cases. Therefore histopathology should be restricted to only those specimens which reveal a macroscopic abnormality. ${ }^{33}$ The question of a selective approach to sending all GBs for histology following cholecystectomy has been postulated in many journals but as yet no guidelines have been published in light of such concern. 33

The only effective treatment for GBC is operative resection, and an open technique is preferred. Unfortunately, as is often the case, the lack of presurgical differential diagnosis hampers the planning of surgery. ${ }^{34}$ Evidence has emerged that suggests early GBC (pT1) need not be treated further than the cholecystectomy that was previously performed in order to obtain the tissue sample. In other words, although early macroscopic findings indicative of GBC could theoretically be missed in a selective method, no further treatment is necessary in such early pathogenic stages. ${ }^{35}$ In this study $84.62 \%$ cases were in $\mathrm{pT}_{1}$ stage.

According to this study incidence of GBC is very high on thick walled GB. But we found two patients of GBC having normal wall thickness. So we recommend all resected specimen should be examined histopathologically.

\section{Conclusion:}

Diffuse GB wall thickening can result from a broad spectrum of pathological conditions, including surgical and non-surgical diseases. GBC may present as focal or diffuse asymmetric wall thickening or even in GB having normal wall thickness. Combined with well known risk factors such as increasing age, female sex, ethnicity and working on a when-in-doubt policy whereby if there are any suspicions whether small or large, all GB should be sent for histology, thus clinicians will be able to put into action a more evidence-based approach to send specimens to pathology.

\section{References:}

1. A. Jemal, R. Siegel, E. Ward et al. "Cancer statistics, 2006," Ca-A Cancer Journal for Clinicians, 2006, vol. 56, no. 2, p. 106-130.

2. Abhishek Vijayakumar, Avinash Vijayakumar, Vijayraj Patil, M. N. Mallikarjuna, and B. S. Shivaswamy. Early Diagnosis of Gallbladder Carcinoma: An Algorithm Approach, ISRN Radiology, Volume 2013, Article ID 239424, 6 pages.

3. M. I. M. De Zoysa, S. K. L. A. De Silva and A. Illipe-ruma. Is Routine Histological Examination of the Gall-bladder Specimens Justifiable? Ceylon Medical Journal, 2010, Vol. 55 , No. 1 , p. 3-16.

4. V. Nagaraja and G. D. Eslick. Systematic review with metaanalysis: the relationship between chronic Salmonella typhi carrier status and gall-bladder cancer. Alimentary Pharmacology \& Therapeutics, April 2014, Volume 39, Issue 8 , pages $745-750$.

5. Nath G, Singh YK, Kumar K, et al. Association of carcinoma of the gallbladder with typhoid carriage in a typhoid endemic area using nested PCR. J Infect Dev Ctries 2008; 2: 302-7.

6. Jin K, Lan H, Zhu T, He K, Teng L. Gallbladder carcinoma incidentally encountered during laparoscopic cholecystectomy: how to deal with it. Clin Transl Oncol. 2011 Jan;13(1):25-33.

7. Wei-Jie Zhang, Gui-Fang Xu, Xiao-Ping Zou, Wei-Bing Wang, Jun-Chi Yu, Guo-Zhong Wu and Chun-Lei Lu. Incidental Gallbladder Carcinoma Diagnosed During or After Laparoscopic Cholecystectomy, World Journal of Surgery, 2009, Volume 33, Number 12 2651-2656]

8. Akyurek N, Irkorucu O, Salman B, Erdem O, Sare M, Tatlicioglu E. Unexpected gallbladder cancer during laparoscopic cholecystectomy. J Hepatobiliary Pancreat Surg. 2004;11:357-361.

9. Malik IA. Clinicopathological features and management of gallbladder cancer in Pakistan: a prospective study of 233 cases. J Gastroenterol Hepatol; 2003; 18(8): 950-3.

10. Adriaan C. van Breda Vriesman, Marc R. Engelbrecht, Robin H. M. Smithuis, Julien B. C. M. Puylaert. Diffuse Gallbladder Wall Thickening: Differential Diagnosis. American Journal of Roentgenology. 2007;188: 495-501.

11. D'Hondt M, Lapointe R, Benamira Z, Pottel H, Plasse M, Letourneau R, et al. Carcinoma of the gallbladder: Patterns of presentation, prognostic factors and survival rate. An 11-year single centre experience. Eur J Surg Oncol. Jun 2013;39(6):548-53.

12. Gore RM, Yaghmai V, Newmark GM, Berlin JW, Miller FH. Imaging of benign and malignant disease of the gallbladder. Radiol Clin N Am 2002; 40:1307-1323.

13. Barbosa ABR, Souza LRMF, Pereira RS, D'Ippolito G. Gallbladder wall thickening at ultrasonography: how to interpret it? Radiol Bras. 2011 Nov/Dez;44(6):381-387. 
14. Miller G, Jarnagin WR. Gallbladder carcinoma. Eur J Surg Oncol. 2008;34:306-312.

15. Duffy A, Capanu M, Abou-Alfa GK, et al. Gallbladder cancer (GBC): 10-year experience at Memorial SloanKettering Cancer Centre (MSKCC). J Surg Oncol; 2008; 98: 485 .

16. Konstantinidis IT, Deshpande V, Genevay M, et al. Trends in presentation and survival for gallbladder cancer during a period of more than 4 decades: a single-institution experience. Arch Surg; 2009; 144: 441.

17. Vivek Trivedi, Vivek V. Gumaste, Shaojun Liu, Joel Baum. Gallbladder Cancer: Adenoma-Carcinoma or DysplasiaCarcinoma Sequence? Gastroenterology \& Hepatology Volume 4, Issue 10 October 2008, p- 735-37.

18. Sivaprakash Rathanaswamy, Sanjeev Misra, Vijay Kumar, Chintamani, Jaipalreddy Pogal, Akash Agarwal, Sameer Gupta. Incidentally Detected Gallbladder Cancer - The Controversies and Algorithmic Approach to Management. Indian Journal of Surgery, June 2012, Volume 74, Issue 3, pp 248-254.

19. Eldon A. Shaffer, Gallbladder Cancer: The Basics. Gastroenterology \& Hepatology Volume 4, Issue 10 October 2008, p- 737-41

20. Randi G, Franceschi S, La Vecchia C. Gallbladder cancer worldwide: geo-graphical distribution and risk factors. Int J Cancer. 2006;118:1591-1602.

21. Reid KM, Ramos-De la Medina A, Donohue JH: Diagnosis and surgical management of gallbladder cancer: a review. J Gastrointest Surg 2007; 11: 671-681.

22. Furlan A, Ferris JV, Hosseinzadeh K, Borhani AA: Gallbladder carcinoma update: multimodality imaging evaluation, staging, and treatment options. AJR Am J Roentgenol; 2008; 191(5): 1440-7.

23. Rodríguez-Fernádez A, Gómez-Río M, Medina-Benitez A, et al.: Application of modern imaging methods in diagnosis of gallbladder cancer. J Surg Oncol; 2006; 93: 650-664.

24. Mohamed A, Emran F, Ghanem N, Mohamed A: Gallbladder Carcinoma, Improving Diagnosis and Outcome. The Internet Journal of Surgery; 2010; Volume 23, Number 2.

25. F. Emran, S.Y. AL_shami, M. Abukhater, K. ALMohaimeed, A.A. Mohamed: Port-Site Metastasis From Gallbladder Carcinoma After Laparoscopic
Cholecystectomy, Report Of Three Cases. The Internet Journal of Surgery. 2010 Volume 25 Number 2.

26. Van Breda Vriesman AC, Engelbrecht MR, Smithuis RH, Puylaert JB. Diffuse gallbladder wall thickening: differential diagnosis. AJR 2007; 188:495 -501.

27. Soo Jin Kim, Jeong Min Lee, Jae Young Lee, Se Hyung Kim, Joon Koo Han, Byung Ihn Choi and Jin Young Choi, Analysis of Enhancement Pattern of Flat Gallbladder Wall Thickening on MDCT to Differentiate Gallbladder Cancer from Cholecystitis, American Journal of Roentgenology. 2008;191: 765-771.

28. B. J. Fahey, R. C. Nelson, D. P. Bradway, S. J. Hsu, D. M. Dumont, and G. E. Trahey, "In vivo visualization of abdominal malignancies with acoustic radiation force elastography," Physics in Medicine and Biology, 2008, vol. 53, no. 1, p. 279-293.

29. S. H. Cho, J. Y. Lee, J. K. Han, and B. I. Choi, "Acoustic radiation force impulse elastography for the evaluation of focal solid hepatic lesions: preliminary findings," Ultrasound in Medicine and Biology, 2010, vol. 36, no. 2, pp. 202-208.

30. Atul Kapoor, Aprajita Kapoor, and Goldaa Mahajan, Differentiating Malignant From Benign Thickening of the Gallbladder Wall by the Use of Acoustic Radiation Force Impulse Elastography, JUM November 1, 2011 vol. 30 no. 11 1499-1507.

31. Altun E, Semelka RC, Elias J. Acute cholecystitis: MR findings and differentiation from chronic cholecystitis. Radiology 2007; 244:174-183.

32. Smith EA, Dillman JR, Elsayes KM, Menias CO, Bude RO. Cross-sectional imaging of acute and chronic gallbladder inflammatory disease. AJR Am J Roentgenol 2009; 192:188-196.

33. Mittal R, Jesudason MR, Nayak S. Selective histopathology in cholecystectomy for gallstone disease. Indian J Gastroenterol. 2010 Jan;29(1):26-30.

34. Jian-Bin $\mathrm{Hu}, \mathrm{Xiao}-\mathrm{Nan}$ Sun, Jing Xu, Chao He. Port site and distant metastases of gallbladder cancer after laparoscopic cholecystectomy diagnosed by positron emission tomography, World J Gastroenterol. Nov 7, 2008; 14(41): 6428-6431.

35. John-Patrick Devine Byars, Kishore Pursnani. An Alternative Approach to Sending All Gallbladders for Histology Following Cholecystectomy? Surgical Science, 2012, 3, 15-20. 